\title{
Don d'organes, consentement et déchirements des proches
}

Jean Martin

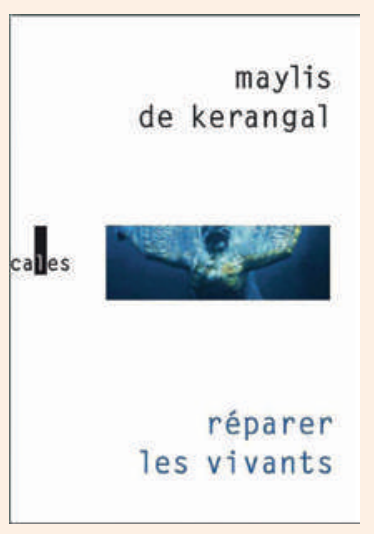

Maylis de Kerangal Réparer les vivants Paris: Gallimard. Editions verticales; 2014 281 pages. 18.99 Euros. ISBN 978-2-0701-4413-6

\footnotetext{
* Et ici et là des notations surprenantes. On permettra au Vaudois qui signe cette recension de relever, alors qu'est évoquée à propos d'un sujet particulier l'année 1959, cette mention: «année du premier vote des Suissesses dans le canton de Vaud»...
}

Maylis de Kerangal (1967) est une éditrice et écrivain française. Elle a publié plusieurs livres qui ont retenu l'attention, notamment «Naissance d'un pont», Prix Medicis 2010. Son dernier roman (qui a reçu sept prix littéraires en quelques mois au printemps 2014!) est l'histoire de Simon Limbres, surfeur passionné de dix-neuf ans de la région du Havre (qui est celle de l'auteure), qui arrive en coma dépassé à l'hôpital de cette ville suite à un accident de la circulation. Kerangal fait vivre ce drame de manière très vraisemblable, prenante: le vécu de l'entourage (parents surtout, sœur, amie, d'autres encore) et celui des professionnels de santé qui l'accueillent et cherchent à le sauver mais voient rapidement que ce n'est pas du domaine du faisable. Les relations entre ces personnes, dans ce qu'on a envie d'appeler une épopée, sont marquées par le fait que Simon est un donneur d'organes potentiel.

Du côté des soignants on trouve le patron du service de réanimation, une infirmière et particulièrement l'infirmier coordinateur des prélèvements d'organes et de tissus (un des 300 de France) - à certains égards le «héros» de l'histoire. Dont la formation et la fonction incluent «relations aux proches, psycho- dans une autre partie de la France, en l'espace de vingt-quatre heures.

C'est ma première lecture de Maylis de Kerangal; j'ai trouvé excellemment écrit, attachant, jamais long; alternant les scènes dans divers services hospitaliers et situations médicales, dans l'appartement familial, à l'extérieur (y compris les premières pages sur le surf téméraire et réussi, en pleine nuit, de Simon et de deux amis). Surtout, Kerangal est de ces auteurs qui effectuent un travail majeur de recherche sur le monde qu'ils investissent, ici celui des urgences/réanimation et de la médecine de transplantation (y compris les procédures et gestes de prélèvement des organes et de transplantation). Les préoccupations des professionnels de santé sont bien exposées: leur souci du patient en coma dépassé comme de son entourage, la volonté de respecter pleinement leurs droits et intérêts tout en ayant à l'esprit le problème du manque d'organes et l'intérêt général, ou en tout cas celui de centaines/milliers de personnes en attente d'un organe. A noter un passage tout à fait intéressant - et amusant (p. 221-227), sur la participation de patients simulés dans la formation médicale.

\section{«Kerangal a voulu une histoire dont tous les personnages sont professionnellement qualifiés et compétents.»}

logie, droit, dimension collective de la démarche [...] et, autre chose de plus complexe, ce tâtonnement singulier au seuil du vivant, le questionnement sur le corps humain et ses usages, l'approche de la mort et ses représentations».

Kerangal a voulu une histoire dont tous les personnages sont professionnellement qualifiés et compétents. On pourra trouver un peu simple mais cela a un côté pédagogique (il y a aussi des éclairages sur les vies privées de ces soignants par touches colorées, sans lourdeur). Les deux parents sont remarquablement dépeints dans le drame qui les assomme d'une minute à l'autre, dans leur révolte et déchirement, puis dans le parcours de quelques heures qui les fait accepter de faire de leur fils un donneur d'organes. Noter que tout cela se déroule, de l'accident à la transplantation cardiaque à une malade receveuse
En plus du plaisir de lire, j'ai ainsi été enrichi par «Réparer les vivants». Figaro.fr parle de Maylis de Kerangal comme du nouveau phénomène littéraire, je me rallie volontiers. On trouve aussi des moments de poésie, des trouvailles (parler de «morse de la médecine» à propos des indications multiples et changeantes apparaissant sur les moniteurs); des descriptions fortes des états d'âme par lesquels passent les protagonistes tempêtes personnelles et familiales. Rien du registre de la sexualitécrasse (plutôt inhabituel aujourd'hui, j'ai trouvé bien agréable)*. En bref, c'est un de ces livres qui, tout en étant fiction, illustrent remarquablement les diverses dimensions de questions médicales et de santé publique. Celles et ceux qu'intéressent les enjeux pratiques, psychologiques, éthiques et sociétaux dont fourmille la médecine d'aujourd'hui seraient bien avisés de mettre ce livre à leur programme de lecture. 